\title{
Reliability Test Rig of the Motorized Spindle and Improvements on Its Ability for High-Speed and Long-Term Tests
}

\author{
Zheng Yang $\left(\mathbb{D},{ }^{1}\right.$ Fei Chen $\left(\mathbb{D},{ }^{2}\right.$ Wei Luo $\mathbb{D},{ }^{1}$ Binbin Xu $\mathbb{D},{ }^{2}$ and Song Wang $\mathbb{D}^{3}$ \\ ${ }^{1}$ Key Laboratory of CNC Equipment Reliability, Ministry of Education, School of Mechanical and Aerospace Engineering, \\ Jilin University, Changchun, China \\ ${ }^{2}$ Sino-German College of Intelligent Manufacturing, Shenzhen Technology University, Shenzhen, China \\ ${ }^{3}$ Lishui Zhejiang Founder Motor Co., Ltd., Lishui, China \\ Correspondence should be addressed to Wei Luo; luoweicn@jlu.edu.cn
}

Received 19 November 2020; Revised 21 December 2020; Accepted 11 January 2021; Published 23 January 2021

Academic Editor: Yiwei Wang

Copyright ( 92021 Zheng Yang et al. This is an open access article distributed under the Creative Commons Attribution License, which permits unrestricted use, distribution, and reproduction in any medium, provided the original work is properly cited.

\begin{abstract}
To realize the accurate performance test under high-speed operation and the long-term stable reliability test of the motorized spindle, a reliability test rig (RTR) which can simulate the cutting force in the actual machining process is presented. Firstly, a reasonable prototype integrating dynamic force loading devices and torque loading devices is designed and established based on the load analysis of the spindle, and a complete and explicit control strategy of the reliability loading test is designed. Secondly, the effects of misalignment of the diaphragm coupling caused by assembling are analyzed, and experiments are conducted to test the axis orbit of the motorized spindle. The experimental results illustrate that the axis orbit can identify the occurrence of misalignment, which ensures timely adjustment of misalignment and the accurate performance test under high-speed operation. Lastly, a damper is added in the mechanical structure of the electrohydraulic servo loading system (EHSLS), and the comparison of Bode maps before and after optimization is analyzed by the Nyquist criterion. After the optimization, the gain and phase margin of the Bode diagram are $12.9 \mathrm{~dB}$ and $57.2^{\circ}$, respectively, which are both within the stable range and validate the improvements on the ability of long-term reliability tests of the motorized spindle. The presented RTR is able to simulate the actual cutting force and provides an efficient loading approach to guarantee the accuracy and stability of motorized spindle tests.
\end{abstract}

\section{Introduction}

As one of the key functional components of CNC machine tools [1-4], the reliability of machine tool spindles has a direct influence on the reliability of the whole machine tool system, so it is of great significance to research the reliability of the motorized spindle [5]. Fundamental studies on reliability need performance and fault data, which are the basis of the subsequent work, such as reliability modeling and analysis [6-8], fault diagnosis, and remaining life prediction [9]. Performance and fault data can be obtained from both field failure records in the workshop [10] and test rigs in the laboratory $[11,12]$. The data collected directly in the workshop are trustworthy and ideal for reliability analysis with the development of big data and sensor technology [13], but it is considerably time consuming and material wasting. In comparison, a reliability test rig (RTR) simulating cutting forces for the motorized spindle in the actual machining process is more convenient and environment-friendly to collect the data in a simulation condition that is close to the real working condition [14-16].

The motorized spindle normally experiences cutting forces during its machining process; therefore, the loading device should have the capacity of applying dynamic force on a moving spindle. In recent years, experts have done a lot of research studies on the dynamic loading of the motorized spindle for performance tests and fault data collection $[17,18]$. Matsubara et al. [19, 20] proposed a magnetic loading device to provide swept-sine-wave load to the motorized spindle and studied the stiffness characteristics of the high-speed spindle under the loading state. Wan et al. [21] developed a noncontact electromagnetic loading device to provide desirable excitation and measure the dynamic performances of the spindle system under different rotating 
conditions. Qiu and Liu $[22,23]$ realized the simulation of cutting force for the motorized spindle by employing electromagnetic forces and analyzed the influencing factors to validate the effectiveness of the noncontact electromagnetic loading method. Li et al. [24] proposed a magnetorheological fluid method for dynamic loading tests to effectively predict the life of a high-speed motorized spindle and assess the precision retaining ability. Feng et al. [25] developed a 5-DOF noncontact air film loading device to test the static stiffness of the motorized spindle under high-speed rotation, which forms a static pressure air film between the air film loader and the tested spindle. However, due to the heating problem of the electromagnet, the objects to be loaded in these studies are mostly focusing on the dynamic performances and stiffness characteristics' measurement, which cannot meet the needs of long-term operation of the high-speed motorized spindle reliability test. Besides, the principle is so complicated to exert load accurately, and the size of the noncontact loading device limited by the air gap is too large.

In order to develop a comprehensive test rig with the dynamic loading capacity, which can simultaneously meet the requirements of the performance test and the long-term reliability test of the motorized spindle, a series of studies considering other loading methods are carried out. Guo et al. $[26,27]$ presented a multiaxis loading device (MLD) to simulate the loading condition of an operating feeding system of a machine tool in a real machining process. Hu et al. [28] designed a reliability test rig based on a power dynamometer and piezoelectric loading device to conduct dynamic loading tests of the motorized spindle. Being restricted to the displacement of piezoelectric ceramics, it is hard to meet the rotation characteristic of the high-speed motorized spindle. Chen [29] and Meng et al. [30] modified a dynamometer to make the interdrag loading accurate in the experiment on the high-speed spindle. Jin et al. [31] developed a novel torqueloading method based on a direct torque control strategy for double motorized spindles to apply the actual static and dynamic torque forces and verified the accuracy of the proposed dynamometer system. It can be seen that some researchers have made efforts to establish a comprehensive test rig, such as torque loading connected by a coupling and force loading transmitted by a mechanism. However, all the previously mentioned studies suffer from some limitations, and the improvements on its ability for high-speed and longterm tests have been rarely reported.

Therefore, considering the functional demands comprehensively, an RTR which can exert both dynamic force load and torque load is designed and established with a complete and explicit control strategy. To improve the ability for accurate performance tests at high speed, the effects of misalignment of the diaphragm coupling are analyzed, and experiments were conducted to identify the occurrence of misalignment. To enhance the stability of the long-term reliability test, a damper is added in the mechanical structure of the EHSLS, and the effectiveness is verified by the Nyquist criterion.

The remainder of this paper is organized as follows: Section 2 describes the prototype and compositions of the
RTR. In Section 3, a 3-DOF model of the diaphragm coupling is established, and the effects of misalignment are analyzed. The mechanical structure of the EHSLS is optimized by the Nyquist criterion in Section 4, and conclusions are drawn in Section 5.

\section{Loading Device Design and Compositions of the RTR}

The function of dynamic force loading and torque loading is integrated into the RTR, and the schematic design is shown in Figure 1. Furthermore, in order to load with accuracy and convenience, the radial and axial force loading device are separately applied on a mechanism, and the torque loading is connected with the running spindle through a coupling.

2.1. Design of Loading Devices. The RTR is aimed at simulating the cutting force as actual as possible, and meanwhile, the failure mechanism of the spindle cannot be changed; thus, the loading device must be designed on the basis of theoretical analysis. The load analyses of typical milling processes are carried out as an example. The load analysis of peripheral milling is shown in Figure 2(a), and the load analysis of face milling is shown in Figure 2(b).

The milling force can be decomposed into three directions, such as main cutting force $F_{x}$, thrust cutting force $F_{y}$, and feed force $F_{z}$, as shown in Figure 1. In order to simplify the loading device and realize the same loading effect, the main cutting force $F_{x}$ and feed force $F_{z}$ are synthesized into a radial force $F_{r}$ which is perpendicular to the axis of the spindle, and thrust cutting force $F_{y}$ parallels to the axis of the spindle which is axial force $F_{a}$. The influence of dynamic load is much greater than that of static load, so the cutting vibration and chatter should not be neglected, and the frequency and amplitude of cutting forces are considered to simulate the dynamic cutting force [32]. Moreover, according to the previous research on the loading spectrum that can reflect the actual milling process [33] in Table 1, an electrohydraulic servo loading system (EHSLS) is chosen as the dynamic loading device because of its compatible frequency, enough force, moderate size, and explicit control strategy.

The friction caused by the contact between the milling tool and the workpiece can generate a friction resistance torque to the center of the spindle, and the ability to resist the friction torque reflects the torque output and loading capacity of the motorized spindle. Inspired by the loading method of motors, a dynamometer is selected as the torque loading device according to the power and speed of the spindle. Besides, the corresponding torque value can be calculated by the radius of the tested spindle end and radial force $F_{r}$ in Table 1.

2.2. Composition of the RTR. The RTR is divided into two parts: the mechanical structure part and the control strategy part. As shown in Figure 3, the mechanical structure part includes the following four systems, such as the supporting system, loading system, force convert system, and accessory system. 


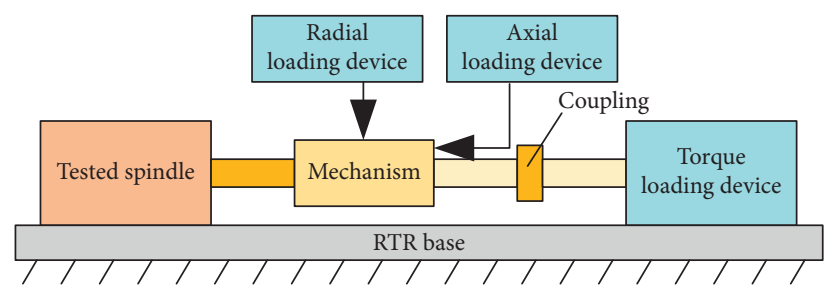

Figure 1: The schematic design of the RTR.

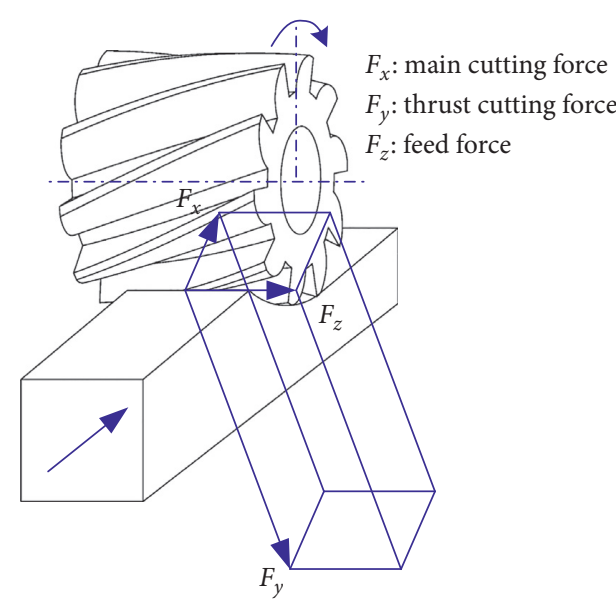

(a)

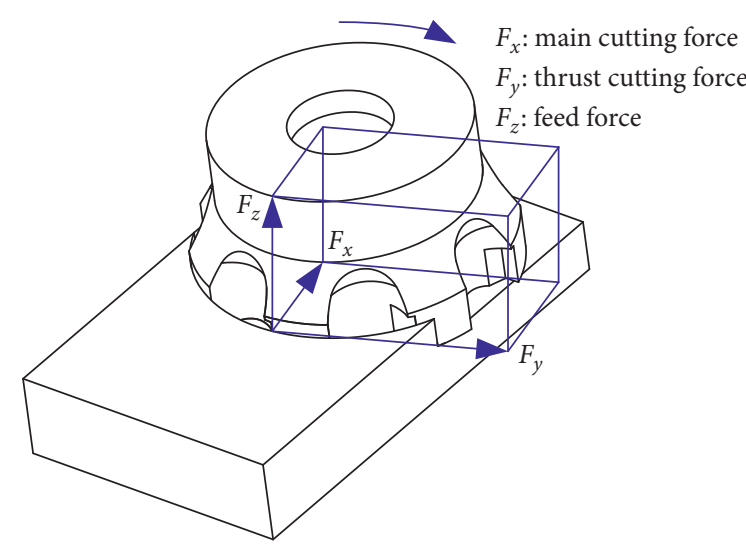

(b)

Figure 2: Load analyses of the milling spindle. (a) Peripheral milling. (b) Face milling.

TABLE 1: Main parameters of the EHSLS.

\begin{tabular}{|c|c|c|c|c|c|}
\hline \multirow{2}{*}{ Speed (r/min) } & \multirow{2}{*}{ Frequency $(\mathrm{Hz})$} & \multicolumn{2}{|c|}{$F_{r}(\mathrm{~N})$} & \multicolumn{2}{|c|}{$F_{a}(\mathrm{~N})$} \\
\hline & & Base value & Amplitude & Base value & Amplitude \\
\hline \multirow{4}{*}{595} & \multirow{4}{*}{10} & -1346.5 & 407.4 & -358.1 & 194.7 \\
\hline & & -673.3 & 219.7 & -179.1 & -108.8 \\
\hline & & 646.4 & 219.7 & 237.5 & 194.7 \\
\hline & & 1292.7 & 473.7 & 475.0 & 225.0 \\
\hline \multirow{4}{*}{950} & \multirow{4}{*}{16} & -820.7 & 235.1 & -279.2 & 44.1 \\
\hline & & -410.4 & 131.5 & -139.6 & 123.0 \\
\hline & & 485.3 & 131.5 & 163.9 & 146.0 \\
\hline & & 970.6 & 243.9 & 329.8 & 246.0 \\
\hline \multirow{4}{*}{1600} & \multirow{4}{*}{27} & -522.6 & 201.6 & -128.3 & -27.8 \\
\hline & & -261.3 & 44.5 & -128.3 & 45.2 \\
\hline & & 229.6 & 98.4 & -64.2 & -27.8 \\
\hline & & 459.2 & 174.7 & 118.0 & 45.2 \\
\hline \multirow{4}{*}{1900} & \multirow{4}{*}{32} & -335.5 & 124.9 & -136.3 & 36.9 \\
\hline & & -167.8 & 71.2 & -136.3 & 73.5 \\
\hline & & 170.5 & 71.2 & 99.5 & 36.9 \\
\hline & & 341.0 & 143.8 & 199.0 & 86.8 \\
\hline \multirow{4}{*}{3000} & \multirow{4}{*}{50} & -232.5 & 89.1 & -48.2 & 10.5 \\
\hline & & -116.3 & 26.9 & 47.1 & 10.5 \\
\hline & & 141.2 & 52.8 & 47.1 & 32.2 \\
\hline & & 282.3 & 103.0 & 94.0 & 75.8 \\
\hline
\end{tabular}




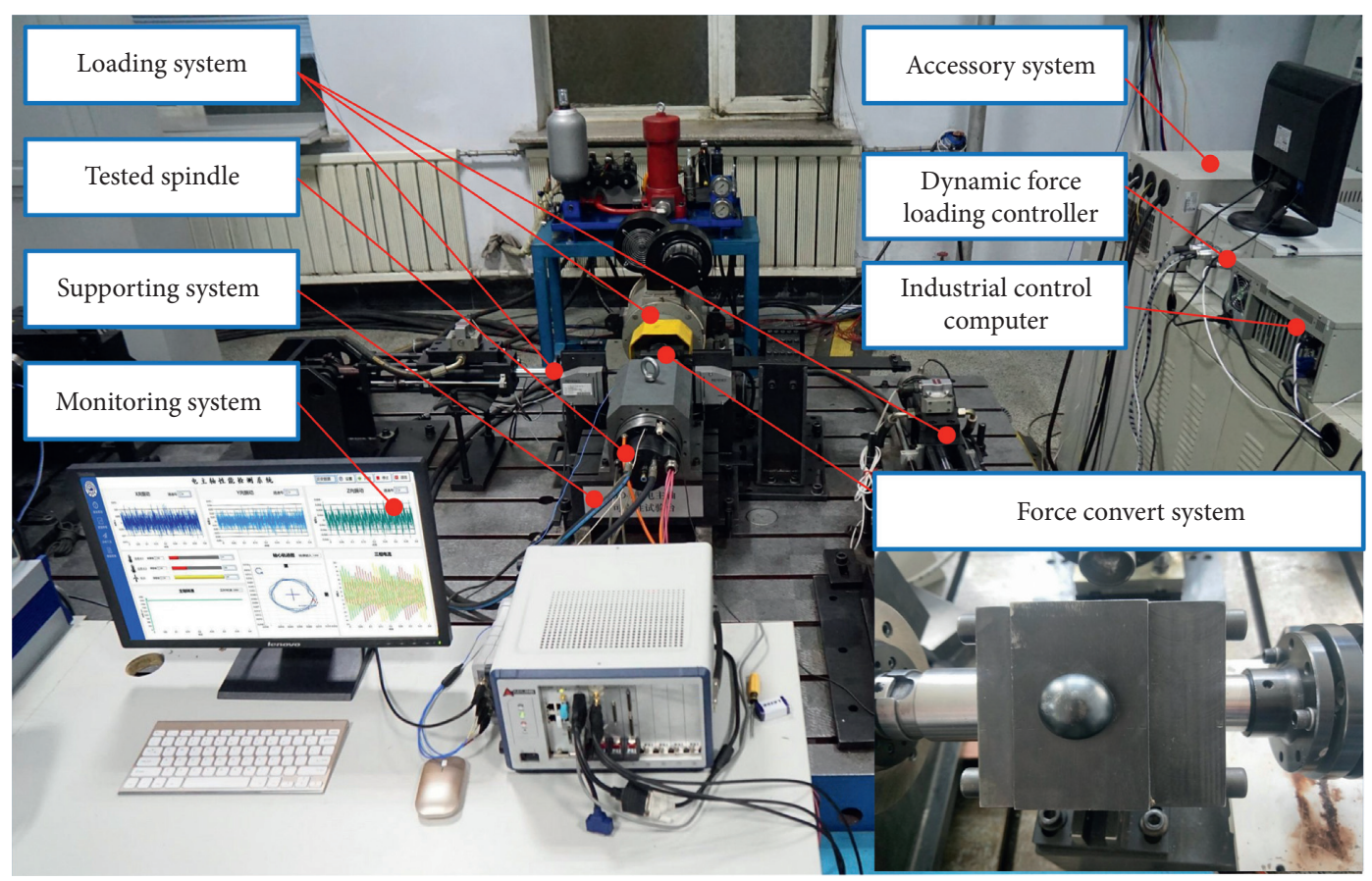

Figure 3: The mechanical structure of the RTR.

2.2.1. Supporting System. The supporting system including the base, pad irons, and the spindle clamping device supports the whole RTR. T-grooves on the base can fix the spindle, the dynamometer, and the loading system for convenience. The spindle clamping device and pad irons are used to fix and clamp different types of motorized spindles and adapt to different center heights.

2.2.2. Loading System. The loading system mainly consists of a radial loading device, an axial loading device, and a dynamometer with a dynamic force loading controller and sensors, which apply feedback to improve loading accuracy. The EHSLS is used as an actuator to simulate dynamic cutting forces and ensure both the amplitude and the frequency for the load spectrum and long-term operation of the reliability test. A dynamometer is used to exert the torque load on the tested spindle, and it takes account of both lowtorque and high-torque loading. In addition, the loading system can not only exert force and torque load simultaneously but also exert them separately.

2.2.3. Force Convert System. The force convert system consists of the bearing unit, the simulated tool, and the diaphragm coupling, and it is loaded by both radial and axial loading devices. As shown in Figure 4(a), the left end of the simulated tool is designed as the standard tool holder which is clamped by the broach mechanism of the spindle. The bearing unit is assembled in the middle of the simulated tool to provide force-exerting points for the running spindle. Double keyways are used on the right end to connect with the elastic diaphragm coupling to transfer torque load from the dynamometer and to avoid imbalance during high-speed rotation. In addition, force loading application on the bearing unit is indicated in Figure 4(b), the radial force loading exerts directly, and the axial force loading exerts on the symmetric raised edges of the bearing unit through a lever, which can change the direction of the axial force and solve the limitations of space. Considering the stability under high-speed rotation and the exertion of axial load, the bearing unit is arranged on the simulated tool with a sleeve and two covers.

2.2.4. Accessory System. The accessory system mainly consists of a cooling system, a lubrication system, and a variablefrequency drive (VFD). The cooling and lubrication system are used to guarantee the long-term operation of reliability tests, and the VFD can control the start-stop and rotation speed of the tested spindle automatically according to the load spectrum program in the industrial control computer. These are also indispensable to ensure normal operation of the RTR.

A control strategy is established corresponding to the mechanical structure part mentioned above, as shown in Figure 5. The start-stop and rotation speed of the tested spindle can be controlled by the VFD, and the running tested spindle is protected by the cooling system and lubrication system of the accessory system. The amplitude and the frequency of the force loading device are controlled by a dynamic force loading controller with the feedback signal from the force sensor and the displacement sensor. A measurement control instrument is used for the dynamometer to exert the required torque load on the running spindle. Otherwise, the monitoring system is used to monitor the characteristic signals of the tested 

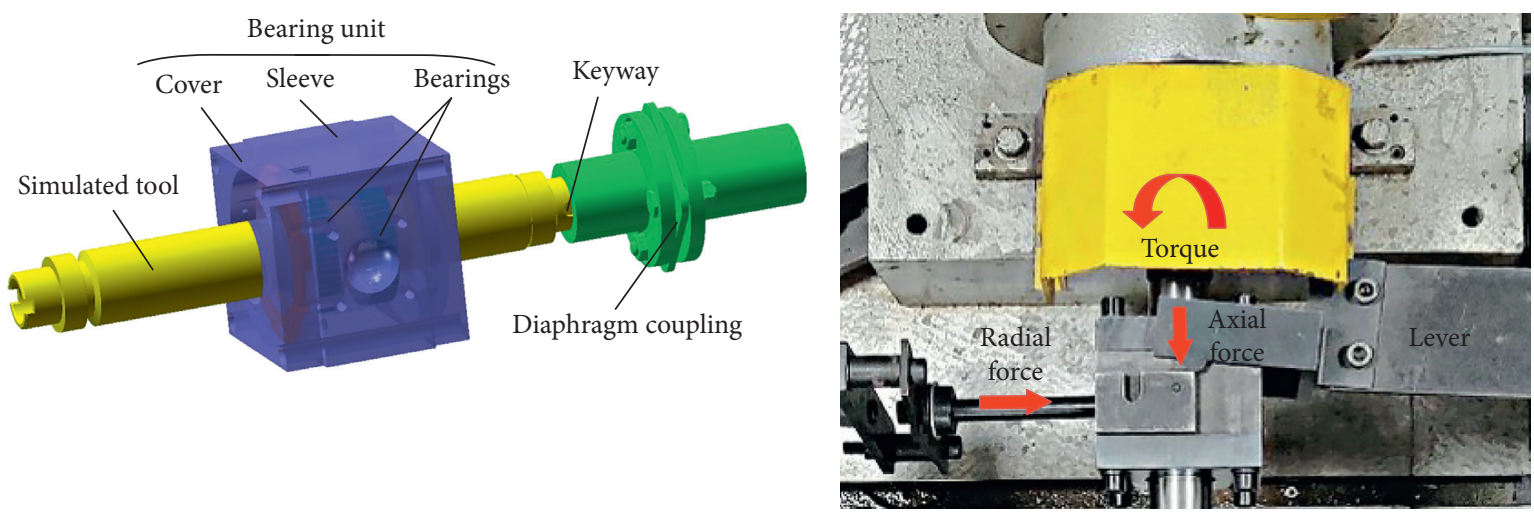

(a)

(b)

Figure 4: force convert system. (a) Structural sketch. (b) Loading application.

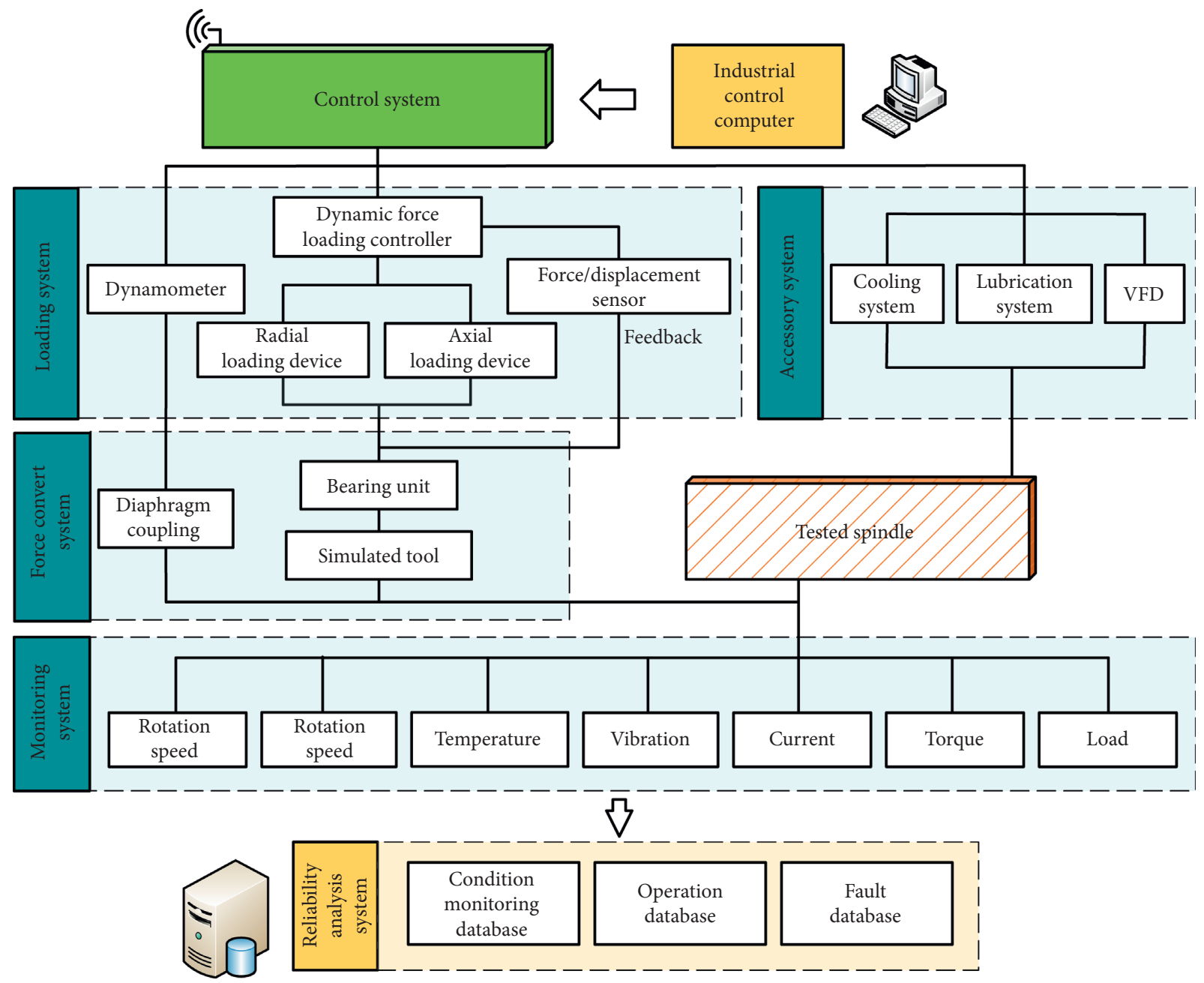

FIgURE 5: The control strategy of the RTR.

spindle by corresponding sensors, such as temperature, current, and vibration. If the tested signal exceeds the value specified in the standard, a fault is diagnosed, and its detailed information is recorded in the fault database. When the reliability test is completed, the running status and the measured characteristic signal are recorded in the operation database and the condition monitoring database, respectively. Ultimately, the comprehensive evaluation of the motorized spindle will be analyzed by the reliability analysis system. 


\section{Influence Analysis of the Misalignment of the Diaphragm Coupling}

As the key component of the force convert system, the diaphragm coupling transmits the torque load from the dynamometer to the tested spindle, and its misalignments generate additional loads on the tested spindle. Bending deformation caused by the additional loads affects the axis orbit which is the most intuitive performance characteristics of the motorized spindle. In addition, abnormal mechanical vibration, noise, and rapid wear of bearings in the force convert system caused by the misalignment affect the development of high-speed reliability experiments. To realize the timely adjustment of misalignment and the accurate performance test under high-speed conditions, the influence of misalignment is analyzed, and the occurrence can be identified by experiments.

3.1. Mathematical Modeling and Simplification. The diaphragm coupling is chosen to connect the simulated tool and the dynamometer due to the advantages of strong adaptability, simple structure, convenient disassembly and assembly, and no need for lubrication. It is an essential part to transmit torque load and compensate the relative axial, radial, and angular displacement through the deformation of a diaphragm group. When the misalignment of the diaphragm coupling occurs, there is a deviation between the actual position and the theoretical position of the two axes, and the deformation of the diaphragm group compensates for the deviation that will produce additional loads that affect the loading accuracy. The additional loads which react on the simulated tool through the driving bolt are finally applied to the tested spindle.

In order to simulate the actual working condition, research on additional loads caused by misalignment is necessary to improve loading accuracy. Therefore, considering the structural characteristics and stress of the diaphragm group, a 3-DOF mathematical model is established, including axial, radial, and tangential, as shown in Figure 6(a). In Figure 6(a), $A, B$, and $C$ represent driven bolts and $m_{1,2,3}$, $k_{1,2,3}$, and $c_{1,2,3}$ represent the equivalent mass, stiffness, and damping in the axial, radial, and tangential direction, respectively.

Our previous study has reported that the misalignment of the diaphragm only causes the deformation in axial and radial directions, and the dynamic parameters in the tangential direction can be ignored [34]. Besides, the dynamic stiffness and static stiffness are equal, and the equivalent mass and damping in the axial and radial direction can also be ignored. Therefore, the mathematical model can be simplified as Figure 6(b), and $k_{r}$ and $k_{z}$ represent stiffness in axial and radial directions which have been calculated in [35]. Then, the expression of the additional load can be simplified as follows:

$$
F(t)=K X(t),
$$

where $F(t)$ is the excitation, $K$ is the axial or radial stiffness, and $X(t)$ is the deformation of the diaphragm group.
3.2. The Calculation Method of the Additional Loads. Each misalignment condition may cause corresponding additional loads on the motorized spindle, so the stress under four conditions is analyzed, respectively, and the calculation formula of the additional load is derived as follows.

3.2.1. Axial Misalignment. The bending deformation of the diaphragm is constant when the axial misalignment of the simulated tool and the dynamometer is fixed and can be expressed as follows:

$$
f_{z}=\delta,
$$

where $f_{z}$ is the axial deformation of the one-side diaphragm and $\delta$ is the value of axial misalignment. According to formula (1), the additional load is derived as follows:

$$
F_{1}=\frac{1}{2} k_{z} f_{z}=\frac{1}{2} k_{z} \delta,
$$

where $F_{1}$ is the additional load caused by axial misalignment, $k_{z}$ is the axial stiffness of the diaphragm group whose value is $93.44 \mathrm{~N} / \mathrm{mm}$, and $\delta$ is the value of axial misalignment.

3.2.2. Radial Misalignment. In the case of radial misalignment, the tension and compression deformations of the diaphragm which can be changed over time are completely symmetrical with respect to the two driven bolts. Therefore, the radial deformation of one side can be denoted as a function of time:

$$
f_{r}=r \cos \omega t,
$$

where $f_{r}$ is the radial deformation of one side, $r$ is the value of radial misalignment, and $\omega$ is the angular velocity. According to formula (1), the additional load is also derived as a function of time:

$$
F_{2}=\frac{1}{2} k_{r} f_{r}=\frac{1}{2} k_{r} r \cos \omega t,
$$

where $F_{2}$ is the additional load caused by radial misalignment, $k_{r}$ is the radial stiffness of the diaphragm group whose value is $457819.33 \mathrm{~N} / \mathrm{mm}, r$ is the value of radial misalignment, and $\omega$ is the angular velocity.

3.2.3. Angular Misalignment. When the angle is misaligned, the bending deformation of the diaphragm coupling is time varying and symmetrical. According to the geometric analysis, which has been proved in our previous work [35], the bending deformation of one side can be expressed as a function of time:

$$
f_{z}=R \sqrt{2-2 \cos \theta} \sin \omega t,
$$

where $f_{z}$ is the bending deformation of one side, $R$ is the distance from the axis of the bolt hole to the axis of rotation whose value is $30 \mathrm{~mm}, \theta$ is the value of angular misalignment, and $\omega$ is the angular velocity. According to formula (1), the additional load is also derived as a function of time: 


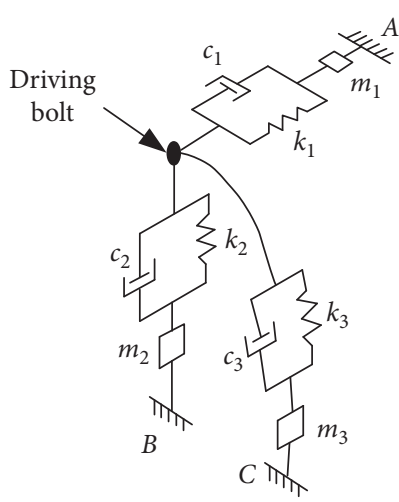

(a)

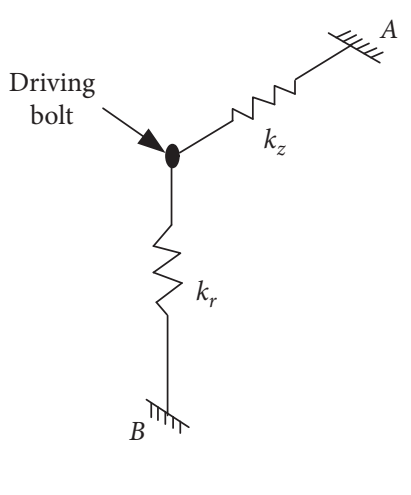

(b)

FIgure 6: The mathematical model of the diaphragm group. (a) The 3-DOF model. (b) The simplified model.

$$
F_{3}=\frac{1}{2} k_{z} f_{z}=\frac{1}{2} k_{z} R \sqrt{2-2 \cos \theta} \sin \omega t
$$

where $F_{3}$ is the additional load caused by angular misalignment, $k_{z}$ is the axial stiffness of the diaphragm group whose value is $93.44 \mathrm{~N} / \mathrm{mm}, R$ is the distance from the axis of the bolt hole to the axis of rotation whose value is $30 \mathrm{~mm}, \theta$ is the value of angular misalignment, and $\omega$ is the angular velocity.

3.2.4. Synthesized Misalignment. The synthesized misalignment can be explained as a superposition of the axial misalignment, the radial misalignment, and the angular misalignment. Therefore, the additional load generated by the synthesized misalignment can be decomposed into the axial additional load and the radial additional load and expressed as follows:

$$
\left\{\begin{array}{l}
F_{a}=\frac{1}{2} k_{z}(\delta+R \sqrt{2-2 \cos \theta} \sin \omega t) \\
F_{r}=\frac{1}{2} k_{r} r \cos \omega t
\end{array}\right.
$$

where $F_{a}$ and $F_{r}$ are the decomposition amount of the additional load generated by the synthesized misalignment in the axial and radial directions, $k_{z}$ is the axial stiffness of the diaphragm group whose value is $93.44 \mathrm{~N} / \mathrm{mm}, k_{r}$ is the radial stiffness of the diaphragm group whose value is $457819.33 \mathrm{~N} / \mathrm{mm}, \delta$ is the value of axial misalignment, $r$ is the value of radial misalignment, $\theta$ is the value of angular misalignment, $R$ is the distance from the axis of the bolt hole to the axis of rotation whose value is $30 \mathrm{~mm}$, and $\omega$ is the angular velocity.

3.3. Experiments and Discussion. Additional loads caused by different misalignment conditions result in different deformations of the shaft as the loads will finally act on the end of the rotating spindle through the coupling, and the corresponding axis orbit is different, which concerns the mechanical performance of the spindle [36]. Therefore, experiments are carried out to study the influence of misalignment on the spindle axis orbit, which provides the basis for timely detection and adjustment of misalignment and ensures the safe high-speed operation and accurate performance test of the reliability test. Interferences of the bearing unit, axial loading device, and radial loading device are removed considering effects on the experiment results, and the simulated tool is only connected to the dynamometer through the coupling. As shown in Figure 7, the test system of the axis orbit is composed of laser displacement sensors, a signal processing unit, a data acquisition unit, a power supply, and an industrial computer. The laser displacement sensors are installed on a specially customized sensor supporting bracket, which machines two vertical grooves within the acceptable error range. Thus, the perpendicularity between the two sensors can be ensured to obtain the horizontal and vertical data, respectively, and the axis orbit can be synthesized after denoising.

According to formula (3) of the axial additional load, the direction and value of the additional load generated by axial misalignment remain unchanged with the increase of rotating speed of the motorized spindle and will not cause abnormal vibration and obvious bending deformation of the rotating shaft. Therefore, axial misalignment is not discussed in experiments. To analyze the relationship between the axis orbit and the misalignment, experiments are divided into four working conditions: good alignment, radial misalignment, angular misalignment, and synthesized misalignment. Moreover, low-speed and high-speed experiments are carried out separately to explore the influence of rotating speed on the axis orbit, which are $1000 \mathrm{r} / \mathrm{min}$ and $5000 \mathrm{r} / \mathrm{min}$, respectively. The maximum misalignment error of the RTR is $20 \mathrm{~mm}$, so the misalignment error value of each working condition is set in the range and realized by the laser centering instrument, as shown in Table 2. It is worth mentioning that the angle error value refers to the tangent value of the angle.

The axis orbits of low-speed and high-speed experiments are shown in Figures 8 and 9, respectively. It can be concluded that the axis orbits of condition 1 are characterized as ellipses which have a smooth profile. Because there is no perfect condition of misalignment, even a small amount of misalignment can cause the noncircular profile. In the case of 

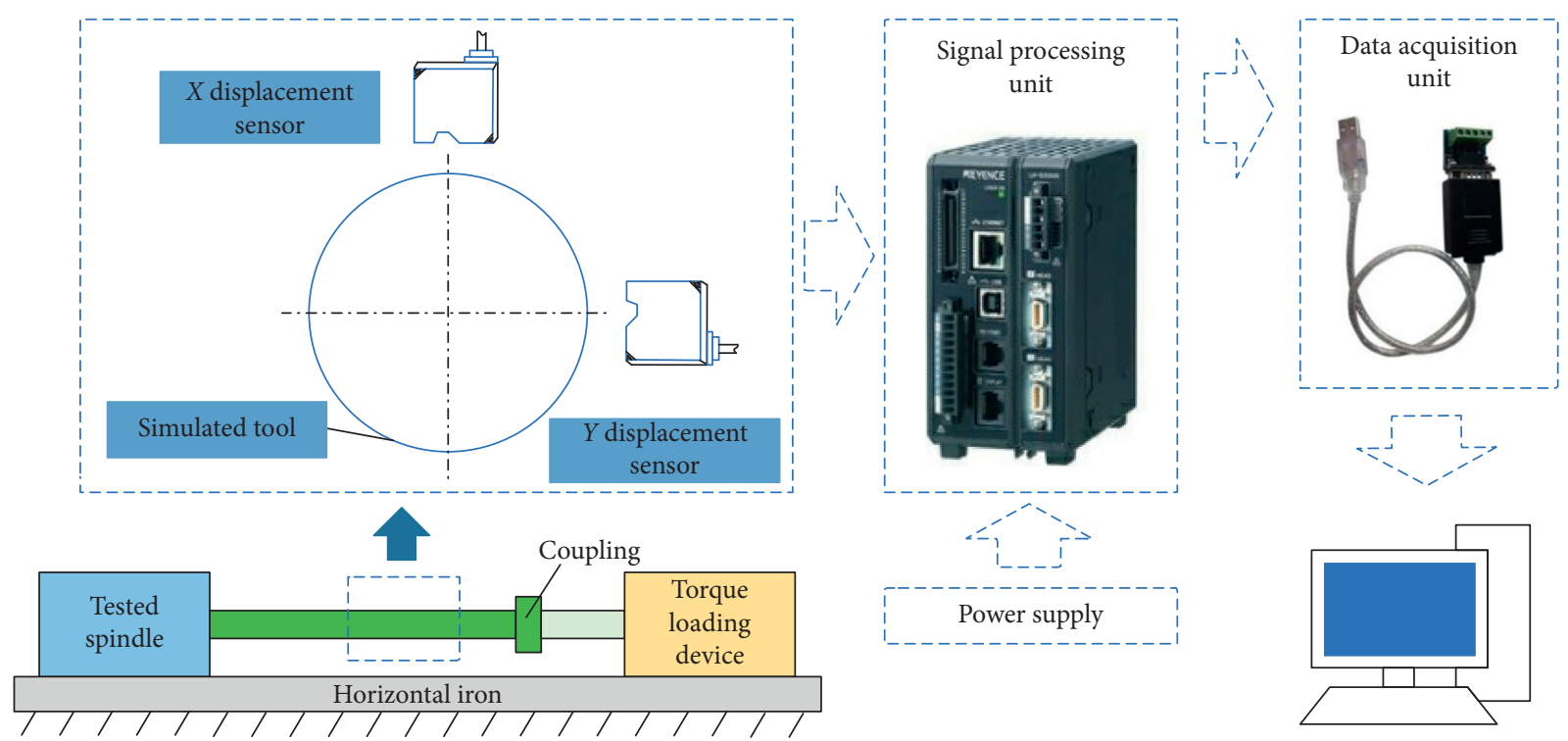

Figure 7: The test system of axis orbits.

TABle 2: Conditions of axis orbits' tests.

\begin{tabular}{|c|c|c|c|c|c|}
\hline Conditions & Speed $(\mathrm{r} / \mathrm{min})$ & Direction & Angle error $(\mathrm{mm} / \mathrm{mm})$ & Radial error (mm) & Description \\
\hline Condition 1 & $\begin{array}{l}1000 \\
5000\end{array}$ & $\begin{array}{c}\text { Vertical } \\
\text { Horizontal } \\
\text { Vertical } \\
\text { Horizontal }\end{array}$ & $\begin{array}{l}-0.01 / 100 \\
-0.02 / 100 \\
-0.01 / 100 \\
-0.02 / 100\end{array}$ & $\begin{array}{l}-0.01 \\
+0.01 \\
-0.01 \\
+0.01\end{array}$ & Good alignment \\
\hline Condition 2 & $\begin{array}{l}1000 \\
5000\end{array}$ & $\begin{array}{c}\text { Vertical } \\
\text { Horizontal } \\
\text { Vertical } \\
\text { Horizontal } \\
\end{array}$ & $\begin{array}{l}-0.02 / 100 \\
-0.01 / 100 \\
-0.02 / 100 \\
-0.01 / 100 \\
\end{array}$ & $\begin{array}{l}-0.06 \\
-0.02 \\
-0.06 \\
-0.02 \\
\end{array}$ & Radial misalignment \\
\hline Condition 3 & $\begin{array}{l}1000 \\
5000\end{array}$ & $\begin{array}{c}\text { Vertical } \\
\text { Horizontal } \\
\text { Vertical } \\
\text { Horizontal }\end{array}$ & $\begin{array}{l}-0.02 / 100 \\
-0.16 / 100 \\
-0.02 / 100 \\
-0.16 / 100 \\
\end{array}$ & $\begin{array}{l}-0.02 \\
-0.01 \\
-0.02 \\
-0.01 \\
\end{array}$ & Angular misalignment \\
\hline Condition 4 & $\begin{array}{l}1000 \\
5000\end{array}$ & $\begin{array}{c}\text { Vertical } \\
\text { Horizontal } \\
\text { Vertical } \\
\text { Horizontal }\end{array}$ & $\begin{array}{l}-0.09 / 100 \\
-0.89 / 100 \\
-0.09 / 100 \\
-0.89 / 100 \\
\end{array}$ & $\begin{array}{l}-0.04 \\
+0.02 \\
-0.04 \\
+0.02 \\
\end{array}$ & Synthesized misalignment \\
\hline
\end{tabular}

condition 2, the diaphragm group generates alternating tension and compression deformation, and the orbit shape directly reflects the additional radial load which always tries to push the rotating shaft to the edge along its direction. Thus, the axis orbits are characterized as ellipses which are flattened on one side, just like the shape of " $D$." In the case of condition 3 , the axis orbits are characterized as combinations of letter " $S$ " and semiellipse whose curvatures suddenly change at some specific positions because the alternating bending deformation generated by the diaphragm group tries to reduce the deflection angle between the two axes. In the case of condition 4, both tension-compression deformation and bending deformation occur alternately at the same time, and the superposition of the two effects results in the complex profile of the orbit shape. Thus, the axis orbits are characterized as profiles out of order just like number " 8 ."

It can also be concluded that the shape of the axis orbits becomes more complex and abnormal with the increase of the severity of the misalignment condition. Taking reference of formulas (5), (7), and (8), the additional load increases with the increase of speed correspondingly, and the runout value becomes larger because of the abnormal vibration. By comparison between Figures 8 and 9, it can be seen that the axis orbit becomes disordered with poor repeatability and wide range.

It can be drawn that different misalignment conditions behave differently because of the direction and value of the additional loads. As the most intuitive performance characteristics of the motorized spindle, it can not only contain rich vibration information in two directions but also can directly reflect the misalignment condition of the RTR in which one-dimensional vibration data cannot reflect. Thus, axis orbits can be regarded as evidence of the occurrence of misalignment, and the condition of misalignment can be distinguished by observing its shape, stability, and repeatability, which is summarized from the above experimental 


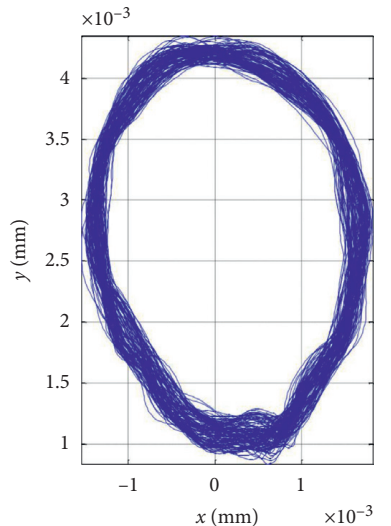

(a)

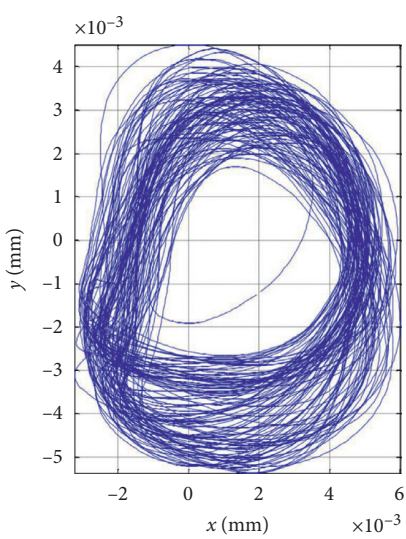

(b)

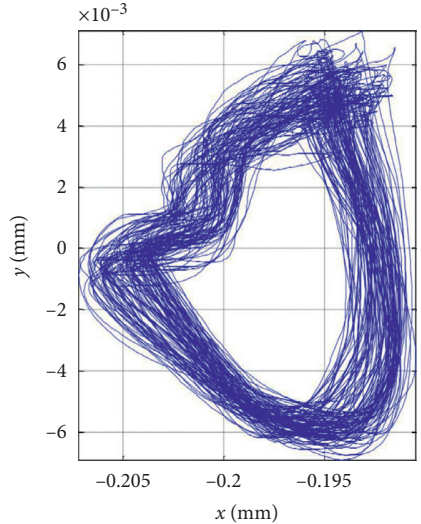

(c)

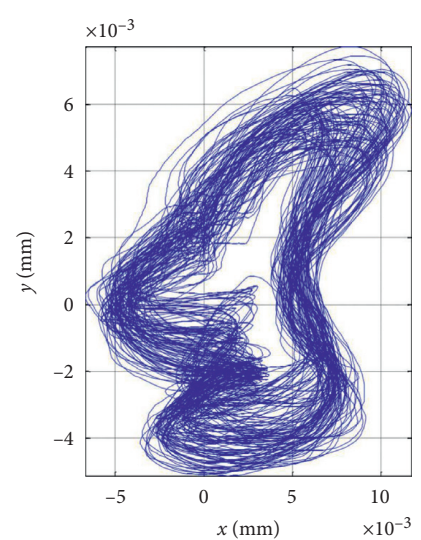

(d)

FIgure 8: Axis orbits of the spindle at $1000 \mathrm{r} / \mathrm{min}$. (a) Condition 1. (b) Condition 2. (c) Condition 3. (d) Condition 4.

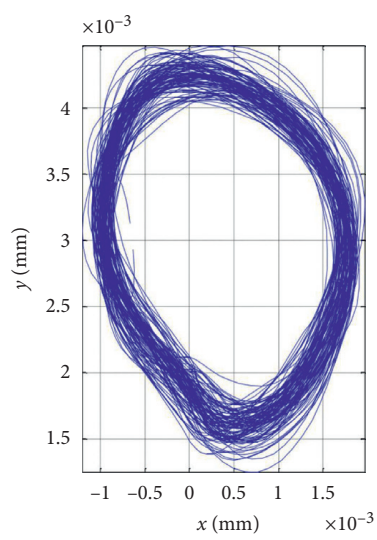

(a)

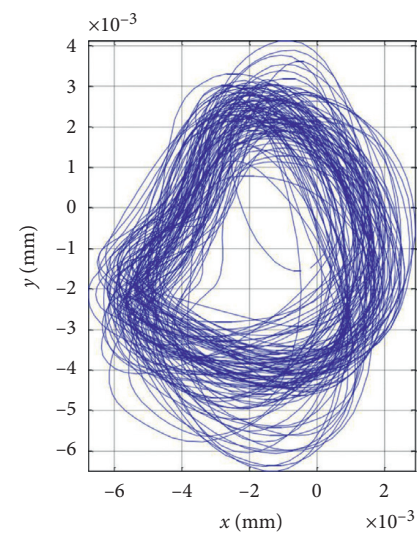

(b)

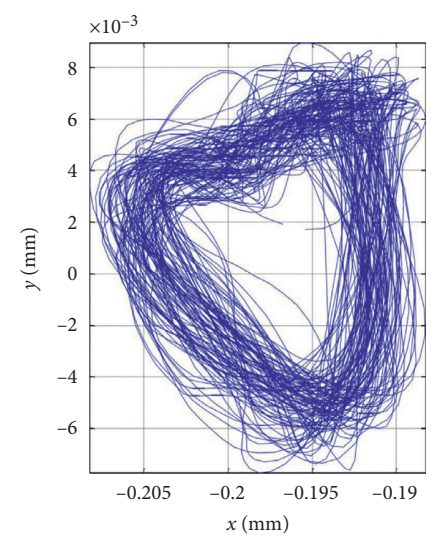

(c)

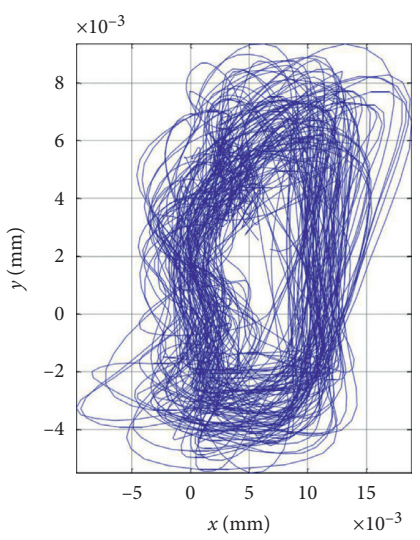

(d)

Figure 9: Axis orbits of the spindle at $5000 \mathrm{r} / \mathrm{min}$. (a) Condition 1. (b) Condition 2. (c) Condition 3. (d) Condition 4.

results. Therefore, misalignment errors can be timely adjusted to realize accurate performance tests under highspeed conditions.

\section{Optimization and Stability Analysis of the EHSLS}

The EHSLS realizing continuous loading of the RTR is a typical feedback control circuit. The long-term rotation of the motorized spindle may produce serious interference, and the additional flow of the EHSLS caused by the interference can result in the generation of additional force which affects the stability of the RTR. Hence, it is necessary to take optimization and analyze the stability of the EHSLS for interference prevention and long-term operation improvement.

4.1. The Elastic System Modeling and Optimization. According to the loading requirement of the motorized spindle, the valve-controlled EHSLS is selected as the loading device to provide dynamic cutting force due to its simple structure and fast response. The signal from the host computer controls the action of the valve spool of the servo valve and the piston of the hydraulic cylinder and acts on the motorized spindle through the intermediate transmission link lastly.

Generally, it is assumed that the intermediate transmission link between the hydraulic cylinder and the tested spindle is rigid, but considering the large number of components and the poor stiffness of certain mechanisms, it is necessary to take the stiffness and damping of the intermediate links into account to analyze the characteristics of the EHSLS. Besides, the friction is neglected, and the simplified elastic model is shown in Figure 10. By modeling the elastic system with structural stiffness $k_{s}$, damping coefficient of the piston, and load $b$, the equilibrium equation is expressed as follows:

$$
A p_{L}=k_{s}+b \dot{y}+m_{p} \ddot{y},
$$

where $A$ is the effective action area of the piston rod, $p_{L}$ is the working pressure of the hydraulic cylinder, $m_{p}$ is the equivalent mass of the piston rod, and $y$ is the displacement of the hydraulic cylinder. 


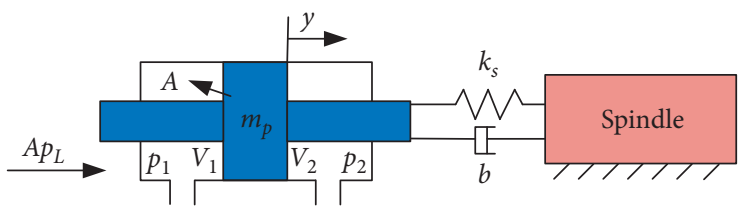

Figure 10: The elastic system considering stiffness and damping.

Taking optimization design of the EHSLS is helpful to improve the stability of the EHSLS and even the loading accuracy. Increasing the damping of the EHSLS is a feasible method, so a damper is added in the mechanical structure part, and the structure of the damper is shown in Figure 11.

4.2. Validation of the Optimized EHSLS by the Nyquist Criterion. According to the flow continuity equations,

$$
k_{q} x=A \dot{y}+\frac{V_{0}}{\beta} \dot{p}_{L}+k_{m} p_{L}
$$

where $x$ is the displacement of the main spool, $k_{m}=L_{m}+$ $L_{0}+k_{L} / 2$ is the leakage coefficient of the system, $L_{m}$ is the internal leakage coefficient of the hydraulic cylinder, $L_{0}$ is the external leakage coefficient of the system, and $k_{L}$ is the flowpressure coefficient.

Then, the open-loop transfer function of the system can be deduced by the relationship among the hydraulic cylinder displacement $Y$, the main spool displacement $X$, the actual loading force $F$, the input current $I$, and the flow Q:

$$
G(s)=\frac{Y(s)}{e(s)}=\frac{k_{a} k_{s y} k_{q} A \cdot\left(b s+k_{s}\right)}{\left[1 / \omega_{V}^{2} s^{2}+2 \xi_{V} / \omega_{V} s+1\right]\left[V_{0} m_{p} / 2 \beta s^{3}+\left(V_{0} b / 2 \beta+k_{m} m_{p}\right) s^{2}+\left(V_{0} k_{s} / 2 \beta+k_{m} b+A^{2}\right) s+k_{m} k_{s}\right]},
$$

where $k_{s y}$ is the gain of the servo-valve control device, $\omega_{V}$ is the natural frequency of the servo valve, and $\xi_{V}$ is the damping coefficient of the servo valve. Besides, $\omega_{V}$ and $\xi_{V}$ are related to the parameters of the servo valve itself and can be obtained from the transient response diagram of the servo valve flow.

For closed-loop control systems with negative feedback, the relationship between the closed-loop transfer function and open-loop transfer function is as follows:

$$
W(s)=\frac{G(s)}{1+G(s) H(s)},
$$

where $H(s)$ is the feedback link of the system.

Therefore, the closed-loop transfer function of the whole system is obtained:

$$
W(s)=\frac{k_{a} k_{s y} k_{q} A \cdot\left(b s+k_{s}\right)}{\left[1 / \omega_{V}^{2} s^{2}+2 \xi_{V} / \omega_{V} s+1\right]\left[V_{0} m_{p} / 2 \beta s^{3}+\left(V_{0} b / 2 \beta+k_{m} m_{p}\right) s^{2}+\left(V_{0} k_{s} / 2 \beta+k_{m} b+A^{2}\right) s+k_{m} k_{s}\right]+k_{a} k_{s y} k_{q} k_{f} A \cdot\left(b s+k_{s}\right)} .
$$

To validate the stability of the optimized EHSLS, the Nyquist criterion is used to analyze the stability of the EHSLS on the Bode map. Considering errors, aging components, and shift characteristics, the stability margins which represent the distance between the system and the stable boundary are used to analyze the stability of the system, such as the gain margin and phase margin. Gain margin $K_{g}$ is the reciprocal of frequency amplitude $|G(j \omega) H(j \omega)|$ that corresponds with the phase crossover frequency $\omega_{g}$, and it is actually the additional gain of frequency amplitude from the stable boundary:

$$
K_{g}=\frac{1}{|G(j \omega) H(j \omega)|} .
$$

Phase margin $\gamma$ is the additional phase lag from the stable boundary at the gain crossover frequency $\omega_{c}$ :

$$
\gamma=\varphi\left(\omega_{c}\right)-\left(-180^{\circ}\right)=180^{\circ}+\varphi\left(\omega_{c}\right) \text {. }
$$

If the gain and phase margin are both positive when the system is open-loop stable, the system is closed-loop stable; if not, the system is closed-loop unstable. As a rule of thumb, the system can obtain greater stability and dynamic performance when $K_{g} \geq 6 \mathrm{~dB}$ and $\gamma \approx 30^{\circ} \sim 60^{\circ}$.

According to equation (11), the Bode diagram before and after optimization is drawn in Figures 12 and 13 for comparison, and the stability margin can be calculated to analyze 


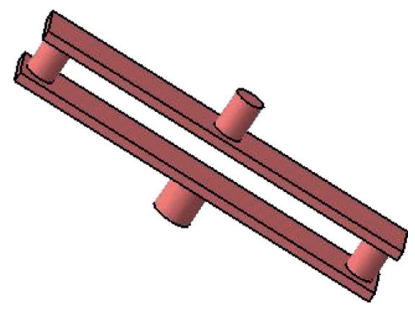

(a)

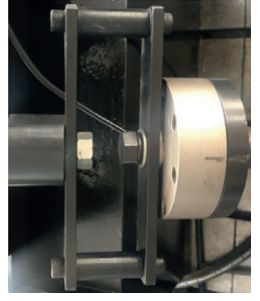

(b)

Figure 11: The structure of the damper. (a) The 3-dimensional model. (b) The prototype of the damper.

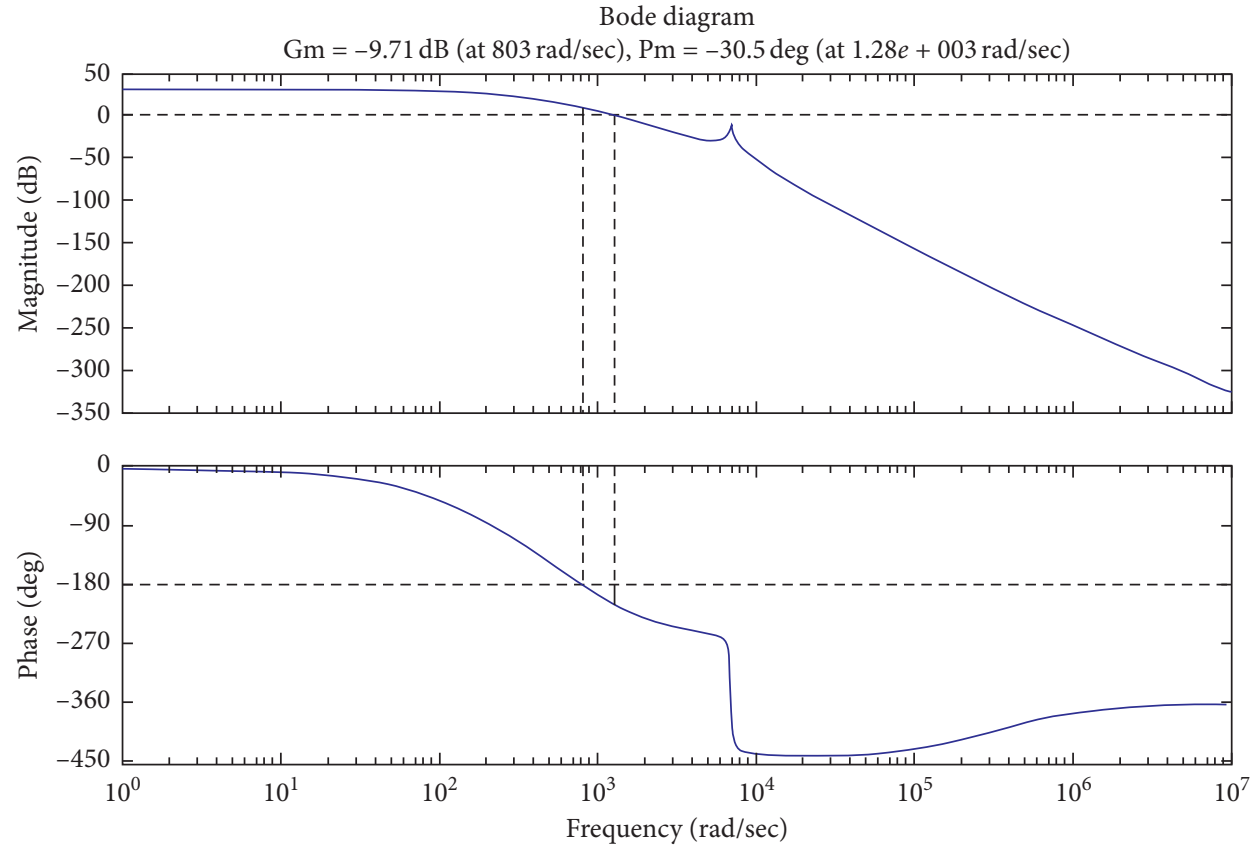

FIgURE 12: The Bode diagram of the EHSLS before optimization.
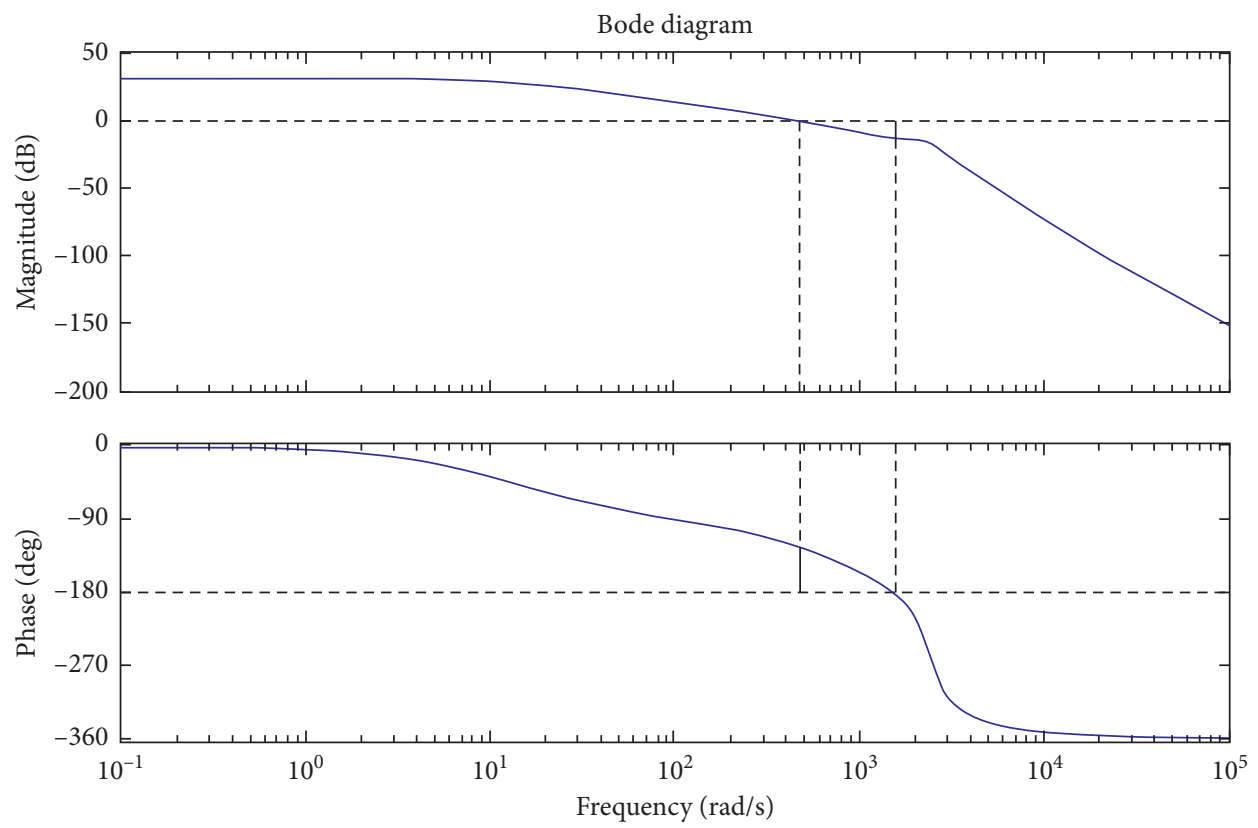

FIgURE 13: The Bode diagram of the EHSLS after optimization. 
TABLE 3: Parameters of the EHSLS before and after optimization.

\begin{tabular}{|c|c|c|c|c|}
\hline Parameter & & Value & Unit & Definition \\
\hline \multirow{12}{*}{ Main parameters } & $k_{a}$ & 13 & $\mathrm{~mA} / \mathrm{V}$ & Amplification coefficient \\
\hline & $\omega_{V}$ & 108.28 & $\mathrm{rad} / \mathrm{s}$ & Natural frequency of the servo valve \\
\hline & $\xi_{V}$ & 0.91 & & Damping coefficient of the servo valve \\
\hline & $k_{q}$ & $8.17 \times 10^{-5}$ & & Flow gain of the servo valve \\
\hline & $k_{m}^{q}$ & $9.92 \times 10^{-12}$ & & Leakage coefficient of the system \\
\hline & $\beta$ & $1.05 \times 10^{-9}$ & $\mathrm{~Pa}$ & Elastic modulus of effective volume \\
\hline & $V_{0}$ & $1.26 \times 10^{-4}$ & $\mathrm{~m}^{3}$ & Oil volume in each chamber when the piston is in the middle of the cylinder \\
\hline & $m_{p}$ & 2.25 & $\mathrm{~kg}$ & Equivalent mass of the piston rod \\
\hline & $A$ & $8.37 \times 10^{-4}$ & $\mathrm{~m}^{2}$ & Effective action area of the piston rod \\
\hline & $k_{s}$ & $2.32 \times 10^{4}$ & $\mathrm{~N} / \mathrm{mm}$ & Structural stiffness \\
\hline & $b^{s}$ & 380 & & Damping coefficient of the piston and load \\
\hline & $k_{f}$ & $4 \times 10^{-4}$ & $\mathrm{~V} / \mathrm{N}$ & Amplification coefficient of the feedback link \\
\hline \multirow[t]{2}{*}{ Damper parameters } & $k_{\mathrm{d}}$ & 1480 & \multirow[t]{2}{*}{$\mathrm{N} / \mathrm{mm}$} & Stiffness of the damper \\
\hline & $b_{d}$ & 1732 & & Damping coefficient of the damper \\
\hline
\end{tabular}

the stability of the closed-loop system by the Nyquist criterion. Moreover, the main parameters of the EHSLS are given, as shown in Table 3, which are the same before and after optimization. For optimization, a damper with the stiffness of $1480 \mathrm{~N} / \mathrm{mm}$ and damping of 1732 is added, and the parameters of the damper are also listed in the bottom of Table 3.

It can be seen in Figure 12 that the gain and phase margin of the Bode diagram are both negative, so the system is closed-loop unstable before optimization. A damper with the stiffness of $1480 \mathrm{~N} / \mathrm{mm}$ and damping of 1732 is added for optimization which can protect the tested spindle and increase the loading stroke of the oil cylinder to improve the loading accuracy indirectly. As shown in Figure 13, the gain and phase margin of the Bode diagram are $12.9 \mathrm{~dB}$ and $57.2^{\circ}$, respectively, which are both within the stable range after optimization. By comparison, the EHSLS has a more stable performance after optimization and can prevent interference and improve the ability of long-term reliability tests.

\section{Conclusions}

Until now, there is little research on the development of the comprehensive test rig for the motorized spindle. To simulate the dynamic force load and the torque load, an RTR for the motorized spindle is designed and established based on the load analyses and loading spectrum of typical milling processes, and a complete and explicit control strategy of the reliability loading test is designed to realize the centralized control of all components of the RTR. By placing the EHSLS as dynamic force loading devices and dynamometer as the torque loading device, this RTR aims to run accurate performance tests and stable reliability tests under high-speed and long-term conditions. With this newly built RTR, two typical and important problems are analyzed, and some conclusions can be drawn as follows:

(1) The RTR presented is able to simulate the cutting forces with sufficient generality, reasonable loading method, and it meets the needs of comprehensive tests, such as performance tests and long-term reliability tests of the motorized spindle.
(2) The effects of misalignment of the diaphragm coupling caused by assembling are analyzed, and a 3DOF mathematical model is established and simplified for the exact time-dependent calculation method of additional loads. It can be concluded that the axis misalignment has little effect on the motorized spindle and can be ignored. Experimental results under different test conditions validate that other misalignment conditions can be distinguished by axis orbits which have proved to be the evidence of the occurrence because of the additional loads. Therefore, the typical misalignment conditions can be recognized and adjusted timely to ensure the accurate performance test under high-speed operation.

(3) The EHSLS is modeled as an elastic system, and a damper is added for optimization. The comparison of the Bode diagram before and after optimization is analyzed by using the Nyquist criterion. The gain and phase margin after optimization are $12.9 \mathrm{~dB}$ and $57.2^{\circ}$ which are within the stable range, while the gain and phase margin before optimization are both negative. It proves that the optimized EHSLS has better stability to prevent interference and improve the ability of long-term reliability tests.

Taken together, the RTR provides a capable and credible method to collect performance and fault data under high-speed and long-term conditions. Moreover, these findings provide a reference for large-scale rotating test rigs with strong stiffness in improving their ability and performance.

\section{Data Availability}

The data used to support the findings of this study are included within the article.

\section{Disclosure}

Zheng Yang and Fei Chen are the co-first authors. 


\section{Conflicts of Interest}

The authors declare that they have no conflicts of interest regarding the publication of this paper.

\section{Authors' Contributions}

Zheng Yang and Fei Chen contributed equally to this work.

\section{Acknowledgments}

This work was supported by National Science and Technology Major Project of China (Grant no. 2018ZX04039001), Characteristic Innovation Projects of Universities of Guangdong Province (Grant no. 2020KTSCX127), and the School-Enterprise Cooperation Research Foundation of Shenzhen Technology University for Graduate Students (Grant no. XQHZ202003).

\section{References}

[1] E. Abele, Y. Altintas, and C. Brecher, "Machine tool spindle units," CIRP Annals, vol. 59, no. 2, pp. 781-802, 2010.

[2] A. Z. Keller, A. R. R. Kamath, and U. D. Perera, "Reliability analysis of CNC machine tools," Reliability Engineering, vol. 3, no. 6, pp. 449-473, 1982.

[3] J. R. W. Merrick, R. Soyer, and T. A. Mazzuchi, "A Bayesian semiparametric analysis of the reliability and maintenance of machine tools," Technometrics, vol. 45, no. 1, pp. 58-69, 2003.

[4] W. Shan, X. Chen, Y. He, and J. Zhou, "A novel experimental research on vibration characteristics of the running highspeed motorized spindles," Journal of Mechanical Science and Technology, vol. 27, no. 8, pp. 2245-2252, 2013.

[5] X. He, "Recent development in reliability analysis of NC machine tools," The International Journal of Advanced Manufacturing Technology, vol. 85, no. 1-4, pp. 115-131, 2016.

[6] X. Li, Z. Yang, C. Chen et al., "A composite model of field reliability based on a generalized Arrhenius model and a support vector machine model for spindle systems," Advances in Mechanical Engineering, vol. 10, no. 9, Article ID 168781401880125, 2018.

[7] M. B. Jun, O. Burak Ozdoganlar, R. E. DeVor, S. G. Kapoor, A. Kirchheim, and G. Schaffner, "Evaluation of a spindlebased force sensor for monitoring and fault diagnosis of machining operations," International Journal of Machine Tools and Manufacture, vol. 42, no. 6, pp. 741-751, 2002.

[8] N.-K. Hsieh, W.-Y. Lin, and H.-T. Young, "High-speed spindle fault diagnosis with the empirical mode decomposition and multiscale entropy method," Entropy, vol. 17, no. 4, pp. 2170-2183, 2015.

[9] M. Baur, P. Albertelli, and M. Monno, "A review of prognostics and health management of machine tools," The International Journal of Advanced Manufacturing Technology, vol. 107, no. 5-6, p. 2843, 2020.

[10] Z. Wang, J. Yang, G. Wang, and G. Zhang, "Application of three-parameter Weibull mixture model for reliability assessment of NC machine tools: a case study," Proceedings of the Institution of Mechanical Engineers, Part C: Journal of Mechanical Engineering Science, vol. 225, no. 11, pp. 27182726, 2011.

[11] J. He, S. Wang, G. Li, Z. Yang, L. Hu, and K. Wu, "Compilation of NC lathe dynamic cutting force spectrum based on two-dimensional mixture models," The International Journal of Advanced Manufacturing Technology, vol. 98, no. 1-4, pp. 251-262, 2018.

[12] Z. Yang, C. Chen, F. Chen, and G. Li, "Progress in the research of reliability technology of machine tools," Journal of $\mathrm{Me}$ chanical Engineering, vol. 49, no. 20, pp. 130-139, 2013.

[13] Y. Wang, Y. Jia, and W. Jiang, "Early failure analysis of machining centers: a case study," Reliability Engineering \& System Safety, vol. 72, no. 1, pp. 91-97, 2001.

[14] W. Su, S. Wan, Y. Sun, J. Hong, and X. Li, "Contactless measurement of spindle stiffness by using lateral stator magnetic loader," in Proceedings of the ASME 2017 International Mechanical Engineering Congress and Exposition, Tampa, FL, USA, November 2018.

[15] R. Sawamura, S. Ikenaga, A. Matsubara et al., "Development of dynamic loading device for rotating spindle of machine tools," in Key Engineering Materials, vol. 523-524, pp. 544-549, Elsevier, Amsterdam, Netherlands, 2012.

[16] S. Tian, X. Chen, Y. He, T. Chen, and P. Li, "A dynamic loading system for high-speed motorized spindle with magnetorheological fluid," Journal of Intelligent Material Systems and Structures, vol. 29, no. 13, pp. 2754-2765, 2018.

[17] D. Zhou, L. Wu, and Y. Xiao, "Comprehensive measurement and evaluation system of high-speed motorized spindle," Frontiers of Mechanical Engineering, vol. 6, pp. 263-269, 2011.

[18] S. Li, L. Xue, Y. Wu, and Z. Ke, "A research on comprehensive performance test system of high-speed motorized spindle," in Proceedings of Third International Conference on Instrumentation, Shenyang, China, 2013.

[19] A. Matsubara, R. Sawamura, K. Asano, and T. Muraki, "Noncontact measurement of dynamic stiffness of rotating spindle," Procedia CIRP, vol. 14, pp. 484-487, 2014.

[20] A. Matsubara, T. Yamazaki, and S. Ikenaga, "Non-contact measurement of spindle stiffness by using magnetic loading device," International Journal of Machine Tools and Manufacture, vol. 71, pp. 20-25, 2013.

[21] S. Wan, J. Hong, W. Su, X. Li, Y. Sun, and W. Chen, "Measurement of dynamic performances of high-speed rotating spindle by non-contact electromagnetic loading device," in Proceedings of the ASME International Mechanical Engineering Congress and Exposition, Proceedings (IMECE), Tampa, FL, USA, vol. 2, 2018.

[22] R. H. Qiu and H. Z. Liu, "Design and implementation of high speed motorized spindle's non-contact electromagnetic loading system," China Mechanical Engineering, vol. 25, no. 8, pp. 1027-1032, 2014.

[23] R. H. Qiu and H. Z. Liu, "Non-contact dynamic electromagnetic loading on high speed motorized spindle," Journal of Vibration, Measurement \& Diagnosis, vol. 34, no. 2, pp. 330-336, 2014.

[24] P. M. Li, X. A. Chen, and Y. He, "Dynamic loading tests of a high speed motorized spindle with magnetorheological fluid," Journal of Vibration and Shock, vol. 34, no. 17, pp. 1-5, 2015.

[25] M. Feng, Y. L. Zhao, W. Yang, and Y. Z. Deng, "The development of non-contact gas-loading system for stiffness measurement of high speed spindles," Machinery Design \& Manufacture, no. 6, pp. 102-105, 2013.

[26] J. Guo, D. Wang, W. Chen, and R. Fan, "Multiaxis loading device for reliability tests of machine tools," IEEE/ASME Transactions on Mechatronics, vol. 23, no. 4, pp. 1930-1940, 2018.

[27] J. Guo, D. Wang, T. Li, S. Gao, W. Chen, and R. Fan, "Triaxial loading device for reliability tests of three-axis machine tools," Robotics and Computer-Integrated Manufacturing, vol. 49, pp. 398-407, 2018. 
[28] Y. Hu, Z. J. Yang, J. A. Song et al., "Design of a reliability test platform for high-speed motorized spindles based on power," Dynamometer and Piezoelectric Loading Systems, vol. 30, no. 1, pp. 34-38, 2012.

[29] F. Chen, Modal and Loading Experimental Study on High Speed Motorized Spindle, Master's Thesis, Chongqing University, Chongqing, China, 2008.

[30] J. Meng, X. A. Chen, H. M. Kang, and F. Chen, "Study on dynamic loading experiment of high speed motorized spindle," Journal of Mechanical Strength, vol. 31, no. 4, pp. 689692, 2009.

[31] T. T. Jin, C. H. Chen, Q. Wang, Z. J. Yang, J. Ying, and S. Z. Li, "Research on the dynamometer system for double motorized spindles," Advances in Mechanical Engineering, vol. 11, 2019.

[32] X. W. Li, X. W. Du, and S. Z. Yang, "Research on characteristics of frequency-domain of cutting force model in milling," Tool Engineering, vol. 34, no. 7, pp. 3-6, 2000.

[33] Y. Li, F. Chen, Y. Song, and W. Luo, "Method of establishing spindle durability test spectrum considering cutting load sequence," in Proceedings of the 2018 12th International Conference on Reliability, Maintainability, and Safety (ICRMS), pp. 266-269, Shanghai, China, October 2018.

[34] F. Chen, F. Bai, C. Chen, S. Wang, and H. Zhang, "Research on double span rotor system driven by motorized spindle with coupling misalignment," Advances in Mechanical Engineering, vol. 11, no. 4, 2019.

[35] S. Wang, "Research on misalignment of rotor system based on motorized spindle reliability test bench,"Master's Thesis, Jilin University, 2016.

[36] W. Chen, Z. Yang, C. Chen, and W. Luo, "Load-dependent rotating performance of motorized spindles: measurement and evaluation using multi-zones error map," IEEE Access, vol. 7, p. 1, 2019. 